- входной контроль. При данном контроле производится анализ сырья, вспомогательных материалов, которые применяются для выпуска продукции;

- контроль качества при проведении технологических процессов;

- контроль качества выпущенной продукции, а также товарной продукции перед отгрузкой потребителям;

- оценка уровня качества по определенным критериям оценки качества.

1. Система менеджмента качества ПАО «Газпром». - URL: https://www.gazprom.ru/about/ms/qualitymanagement-system/

2. Год качества в «Газпроме». - URL: https://www.gazprom.ru/press/news/2018/november/article469297/

3. Тальман А. СМК технологических лидеров. - URL: https://kachestvo.pro/kachestvoupravleniya/sistemy-menedzhmenta/smk-tekhnologicheskikh-liderov

\title{
Муров М.С. \\ Путь к развитию менеджмента, изучение системного и стратегического менеджмента, современные проблемы на предприятиях и пути их решения
}

Сургутский государственный университет (Россия, Сургут)

doi: $10.18411 / 1 j-06-2021-85$

\section{Аннотация}

В статье обсуждаются этапы развития менеджмента, как они видоизменялись и развивались, какие факторы влияли на изменение видов менеджмента, их актуальность, какие проблемы присуще этим видам менеджмента и возможные пути решения данных проблем.

Ключевые слова: Социальный менеджмент, Гуманистический менеджмент, Системный менеджмент, Стратегический менеджмент, проблемы в менеджменте.

\section{Abstract}

The article discusses the stages of management development, how they changed and developed, what kind factors influenced the change in the types of management, their relevance, what problems are inherent in strategic, systemic management and possible ways to solve these problems.

Keywords: Social management, Humanistic management, Systemic management, Strategic management, problems in management.

Главным объектом изучения менеджмента является предприятие производящая и реализующая на регулярной основе продукцию, управляя и координируя работников, ресурсы. В разные периоды времени менеджмент концентрировался на разные аспекты предприятия, такие как на технические, технологические, гуманитарные или социальные функции предприятия.

Функциональный менеджмент - это вид менеджмента, ориентированный на выполнение и удовлетворение целей и функции организации, объектом управления является технико-технологические системы, реализующие этих функций. Для нормального функционирования работники нужны, но считаются как необходимым дополнением для реализации высокотехнологических функций. Основной задачей ставится бесперебойное выполнение профильных функций, т.е. производство и реализация продукции. 
Этот взгляд на производственный процесс доминировал вплоть до первой половины XX, но еще до их начала, в XIX веке, пришло понимание того, что возможности работников предприятия являются ограничением эффективного использования техники.

Гуманистический менеджмент - это вид менеджмента, который направлен обеспечить оптимальную индивидуальную работу или индивидуальный труд работника, мотивацию, взаимоотношения с другими работниками. Делался упор на дальнейший повышение квалификации работника. Активное внедрение новых технологий меняет техническую и технологическую составляющую производства. В связи с часто встречающаяся проблемой как текучесть кадров это в сочетании создает серьезные проблемы во взаимодействии человека и техники. Гуманистический менеджмент пытается решить эту проблему улучшением уровня адаптации у работников, приспособлением их к новой технике.

В капиталистических странах развитие экономики и политики сопровождалось усилением эксплуатации и ухудшением положения рабочих возникло течение, которое рассматривало коллектив не просто как совокупность работников, а как самостоятельный субъект производства.

Социальный менеджмент - это вид менеджмента, кото-рый направлен обеспечить эффективность развития эконо-мики, улучшая работу процесса производства в коллективе наряду с деятельностью, направленной на выполнение определенных экономических результа-тов, постоянно решаются социальные проблемы, пытается построить разнообразные отношения между работниками. Также коллектив уменьшает факторы внешней социальной среды и динамику внутренних изменений на предприятии. Но здесь появляется проблема: не допустить фаворитизма у лидеров по отношению к отдельным взятым работникам и создание чрезмерной конкуренции в коллективе, так как эти факторы будут угрожать устойчивости и в итоге существованию коллектива.

Путем развития менеджмента является синтез старых моделей друг с другом и развитие, инновации в технике и технологии. Здесь можно выделить системный менеджмент как объединение этих факторов в единую систему.

Системный менеджмент - это объединение различных подходов к управлению. Гуманистический и социальный подход, основан на представлении предприятия как технико-технологической и социально-экономической системы. Главной идеей этой системы состоит в том, что изменения или действия в одной сфере организации, будь то экономическая, социальная или техническая, отразится на систему в целом.[1] Реализация этого подхода в наше время находится только на начальной стадии, хотя она уже используется в управлении крупных системах таких как АФК «Система» [2] «,Система" - это огромная компания... и если не внедрить и хорошо не отработать правила управления, то в ручном режиме мы не сможем этого уже делать»., ПАО «КАМАЗ» [3] «Результаты внедрения системы прояви-лись в улучшении показателей деятель-ности компании. »

Эта система получила развитие на таких направлениях как управление бизнеспроцессами, проектный менеджмент, кросс-функционал, развитие культуры в организации и т.д. Распространение данная модель получила с изменениями в социально-экономических системе, исполняющих центральные управленческие роли. В рамках системного менеджмента такие объекты функционального, гуманистического социального менеджмента рассматривается как подсистемы одной, единой системы предприятия. Отсюда и выходит, что основной задачей системного менеджмента является развитие этих подсистем.

С течением времени и развитием менеджмента появляется Стратегический менеджмент. Каждое из перечисленных выше видов менеджмента представляет собой переосмысление имеющихся видов менеджмента. 
Стратегический менеджмент - это вид менеджмента, который основывается на системном менеджменте, так как организация представляется как система, включающая в себя подсистемы и за счет их взаимодействий между собой происходит составление стратегического плана для организации. Основной задачей стратегического планирования является разработка плана, где главное не временные рамки, а планирование основываясь не только от внутренних факторов, но и существенных внешних факторов, которые могут повлиять на результат плана. Тогда стратегия подлежит корректировке. Данный вид менеджмента является наиболее распространенным в России, и на это есть ряд субъективных и объективных причин. К объективным я отношу развитие информационных технологий, развитие сетевой экономики, ускорением научно-технического прогресса. К субъективным я отношу внедрение стратегического менеджмента в образовательные программы для менеджеров, законодательством РФ установлена обязанность предприятий разрабатывать плана, стратегии.[4].

Дальше будут перечисленные основные проблемы, которые свойственны всем видам менеджмента, а потом возможные пути их решения.

1) Граница обязанностей между отделами является проблемным аспектом организации, решение которой может принести стоимости компании до $30 \%$ [5]. Данную проблему можно минимизировать благодаря регламенту, который постарается ясно разграничить права и обязанности подсистем, отделами в организации. Сокращение штата, чтобы облегчить административную нагрузку и упросить коммуникацию между отделами.

2) Малое количество квалифицированных топ-менеджеров [6]. В современном мире работа менеджер рассматривается так, что если человек является руководителем любого уровня управления, то в своей деятельности, чтобы быть успешным и продуктивным, ему необходимы базовые знания в области теории и методологии управления персоналом. Для решения данной проблемы в перспективе поможет улучшить привлечение студентов для практики в свои предприятия и давать им какие-то задания для получения реально первого опыта работы. Также с помощью прямого сотрудничества с компаниями, открывая базовые кафедры. Привлечение самих работодателей к изменению образовательного процесса перспективное решение данной проблемы.

3) Отсутствие продуктивного взаимодействия топ-менеджера и владельца компании [6]. Очень часты конфликты между организацией и топменеджерами, из-за отсутствия взаимопонимания, системы обратной связи и каналов коммуникаций. Выстраивание системы обратной связи поможет ускорить обмен информацией и составить план, так как некоторые внутренние факторы станут известны гораздо быстрее. Общение топ-менеджера и владельца без посредника через каналы коммуникаций также поможет ускорению обмена информацией.

4) Любая проблема может стать серьезной, если пытаться решить, не зная причину её появления. Зная причину, можно найти оптимальное решение для любого рода проблем и придумать меры по быстрому их устранению.

Таким образом можно подвести итоги, что развитие непрерывный процесс. Как происходит НТП, так и развивается все в нашем мире, менеджмент не исключение. В зависимости от того, какие именно системы рассматриваются, какие виды взаимоотношений между этими системами учитываются, возникает разнообразие видов менеджмента будущего. Наиболее значимым на данный момент является системный, 
но есть шансы, что стратегический менеджмент станет доминирующим видом менеджмента в РФ. Основная цель - определить разумные границы систем, которые обеспечили бы решение проблем в управление предприятия с учетом развития сферы общественной жизни.

$$
* * *
$$

1. Центр Креативных Технологий Д. Ямпольская, $\mathrm{M}$ Зонис https://www.inventech.ru/lib/management/management-0009/

2. КиберЛенинка, авторы: И. О. Петров, А.А.Яковлев https://cyberleninka.ru/article/n/rol-sovetadirektorov-v-rossiyskih-rastuschih-kompaniyah-opyt-afk-sistema-chast-i

3. Российский журнал менеджмента, авторы: Е. В. Хомякова Т. Г. Долгопятова https://rjm.spbu.ru/article/view/147

4. КонсультантПлюс http://www.consultant.ru/document/cons_doc_LAW_15234/1c9c247c5480a92d5b05bf126bfabb6b5da08 $169 / \# d s t 131$

5. Технопарк, автор: Н. Хальзова https:/texnopark26.ru/reglament-vzaimodejstviya-mezhdustrukturnymi-podrazdeleniyami-rzhd/

6. NovaInfo, авторы: Ш. Э. Миришли, Николаева Н. А., Толкачева С. Е. Удалов А. А. https://novainfo.ru/article/3983

Никулина Ю.Н., Ищенко В.А.

Процессный подход в системе менеджмента качества: практические вопросы внедрения

Оренбургский государственный университет (Россия, Оренбург)

doi: $10.18411 / \mathrm{j}-06-2021-86$

\section{Аннотация}

Статья посвящена характеристике процессного подхода как принципа и инструмента системы менеджмента качества. Авторы рассматривают способы, с помощью которых процессный подход может помочь внедрить культуру ТQМ и получить сертификацию ISO 9001:2015. Особое внимание обращено на практические примеры использования процессного подхода и некоторые примеры того, как устранить проблемы, которые могут возникнуть при достижении целей в области качества.

Ключевые слова: качество, процессный подход, система менеджмента качества, тотальное управление качеством, принцип постоянного улучшения.

\section{Abstract}

The article is devoted to the characterization of the process approach as a principle and tool of the quality management system. The authors consider ways in which a process-based approach can help implement the TQM culture and achieve ISO 9001:2015 certification. Special attention is paid to practical examples of using the process approach and some examples of how to eliminate problems that may arise when achieving quality goals.

Keywords: quality, process approach, quality management system, total quality management, the principle of continuous improvement.

Исследованию вопросов внедрения системы менеджмента качества посвящены труды многих ученых и специалистов. Методов и инструментов в системе управления качеством есть достаточное количество, каждый из которых в свою очередь имеет свои достоинства и недостатки, специфику и области применения.

Тотальное управление качеством (TQM) - это подход, который фокусирует усилия организации на постоянном улучшении ее способности предоставлять своим 